\title{
O PROFESSOR E A PRÁTICA DOS DEVERES DE CASA: PLANEJAMENTO E AÇÃO EM QUESTÃO
}

\author{
TEACHER AND HIS PRACTICE WITH HOMEWORK: PLANNING AND \\ PEDAGOGICAL ACTION IN QUESTION
}

SCHLINDWEIN, Luciane Maria lucmas@uol.com.br Universidade Federal de Santa Catarina BUENO, Silviane Irulegui silvianeib13@gmail.com

Universidade Federal de Santa Catarina

\begin{abstract}
RESUMO Neste artigo problematizamos uma prática que já se normalizou no cotidiano escolar: os deveres de casa, articulando-os com a formação de professores e a escola. Denominamos deveres de casa toda atividade pedagógica elaborada e proposta pelos professores, para que os alunos realizem em horário opcional, fora do período regular de aulas na escola. Consideramos que a formação do professor é determinante para a relação que este estabelece com os deveres de casa e com a escola, refletindo-se na sua ação docente. A escola é uma instituição com especificidades, diferente da família, com estrutura e funções definidas. É neste sentido que problematizamos os deveres escolares e a formação dos professores, com o intuito de discutir o conhecimento e as relações pedagógicas possíveis, especialmente no âmbito no planejamento. A discussão proposta se ancora na análise de publicações recentes sobre a temática, buscando compreender, na história recente, a função que os deveres vêm desempenhando na prática do professor e sua relação com o planejamento e com os objetivos educacionais.
\end{abstract}

PALAVRAS-CHAVE: Deveres de casa; formação de professores; planejamento pedagógico.

ABSTRACT In this article we question a practice that is already normalized in everyday school: the homework. This subject is linking with the training of teachers and the school. We named homework all pedagogical activity prepared and proposed by teachers, for students to perform in optional time, outside the regular classes in school. We believe that teacher education is crucial to the relationship it establishes with homework and school, reflecting on their teaching activities. The school is an institution with specific, different of 
family, with structure and functions defined. It is in this sense that we question the homework and teacher training, in order to discuss the knowledge and pedagogical relationships possible, especially within the planning. The foregoing discussion is grounded on the analysis of recent publications on the subject, trying to understand, in recent history, how the homework is using in teacher practice and its relationship with planning and educational goals.

KEYWORDS: Homework, teacher training, educational planning

\section{INTRODUÇÃO}

Este texto discute a importância dos deveres de casa no contexto escolar. Partimos do pressuposto de que os deveres de casa passaram a ser uma prática normalizada no interior das escolas, sem constituírem-se como objeto de discussão ou articulação com o planejamento. Neste sentido, os deveres constituem-se em atividade usual que pouco contribui para o favorecimento da aprendizagem ou para o comprometimento dos pais no acompanhamento pedagógico de seus filhos, na escola.

A expressão deveres de casa refere-se a toda atividade pedagógica elaborada e proposta pelos professores, para que os alunos realizem em horário opcional, fora do período regular de aulas na escola.

Considera-se que a prática dos deveres, assim como outras atividades realizadas pelo professor, constitui-se em ação a ser refletida e contextualizada no planejamento escolar, de forma que possa contribuir para a formação integral das crianças. Neste sentido, faz-se necessário pensar na formação política do professor, que ao ter consciência de sua importância na sociedade, deve exercer sua condição humana de ser cidadão, evitando a condição de reprodutor. Fernandes (1987, p. 24) explicita algumas reflexões importantes acerca do assunto, como "Pensar politicamente é alguma coisa que não se aprende fora da prática.", sugerindo que o trabalho do professor deve ir além do ensinar, preocupando-se com o cidadão que quer aprender, com a história de vida de cada um e de que maneira o conhecimento poderá contribuir para mudar as suas vidas. A mudança é um "processo político", o qual envolve escolhas e definições de como se pensa a sociedade, a escola e a educação, e no qual o professor assume suas convicções e torna público como pensa e 
deseja atuar na sociedade em que está inserido. Para isso, "Precisa ter instrumentos intelectuais para ser crítico diante desta realidade e para, nessa realidade, desenvolver uma nova prática, que vá além da escola." (FERNANDES, 1987, p. 30). O professor necessita de formação continuada, de leitura, de estudo, de debate, etc. É necessário estar e fazer parte da sociedade, articulando ideias, propondo reflexão, pensando e repensando-se constantemente.

\section{A ESCOLA E OS DEVERES DE CASA}

Os deveres de casa são propostos na escola, uma instituição social que possui sua organização e forma de funcionar peculiares, sendo possível perceber que há hierarquia nas relações e no poder exercido entre essas hierarquias. Para Cardoso (2004, p. 113) "A escola é um aparelho ou um dispositivo social que se estabelece no capitalismo como um dos pilares da reprodução social [...]".

Como instituição, diferente da família, a escola deve pensar na diversidade de suas crianças, trabalhando de maneira a integrar seus objetivos com as necessidades da população. Miranda (1985, p. 133) destaca três tarefas básicas da escola, a favor dos interesses das classes populares:

[...] facilitar a apropriação e valorização das características socioculturais, garantir a aprendizagem de certos conteúdos essenciais da chamada cultura básica e possibilitar a crítica dos conteúdos ideológicos propostos pela cultura dominante e a reapropriação do saber que já foi alienado das classes populares pela dominação.

A concepção de educação voltada para a cidadania, defendida pelos grandes educadores no Brasil, contrapõe-se à educação formal realizada na escola que, pela sua organização e funcionamento, reproduz e fortalece a relação de dominação.

Atualmente, a contradição está posta entre a formação e a educação enquanto mercadoria. Com as diversas e rápidas mudanças da contemporaneidade, "[...] a escola tende a substituir significativamente a sua 
função instrutora pela função de reprodução das relações sociais [...]" (CARDOSO, 2004, p. 115). Essa "nova" função fixa-se nas tarefas de socialização e de controle social, privilegiando a submissão.

Tanto a pedagogia tradicional como a nova, expressam a ideia de que a escola é uma passagem do mundo infantil para o mundo adulto, reproduzindo o que é esperado da sociedade. Tratado como um estágio de integração da criança à sociedade, o processo de socialização se fez necessário desde que se excluiu a criança do convívio do adulto, diferente do que acontecia na sociedade medieval, na qual o espaço social era compartilhado por todos.

A escola toma para si, na atualidade, a socialização como uma das finalidades, negando que a criança é socializada desde sempre, antes mesmo do nascimento, a partir da história de sua mãe. Essa socialização escolar está intimamente ligada a um comportamento desejado e esperado da sociedade, no qual segundo Miranda (1985, p. 131) "[...] A escola é uma agência socializadora de uma sociedade que se afirma democrática [...]". Portanto, deveria estar mais atenta ao processo de socialização em que é cenário, repensando seus conteúdos, padrões de comportamento e valores sociais, atuando de forma mais crítica e reflexiva, problematizando as situações vivenciadas e possibilitando a convivência respeitosa e não dominadora.

Faz-se necessário pensar sobre o tipo de escola que ajudamos a formar, para que servem e com qual conhecimento estamos trabalhando. Young (2007), ao tratar dessa questão, afirma que é necessário fazer distinção entre duas ideias sobre conhecimento: o "conhecimento dos poderosos" - aquele definido por quem detém o conhecimento, e o "conhecimento poderoso" - é o conhecimento especializado, aquele conhecimento que não é disponível em casa, que as escolas têm como função desenvolvê-los com enfoque nos currículos, conteúdos selecionados e ações intencionais. Esse conhecimento é que permite a construção dos conceitos científicos.

Outro tipo de conhecimento é o cotidiano, o não escolar, que também é importante por auxiliar na formação do aluno, no entanto não é suficiente para a construção de conceitos. Segundo Vigotski (1962 apud Young, 2002, p. 66): 
Enquanto os conceitos científicos têm início com sua definição verbal e se desenvolvem "à medida que são complementados com trabalho escolar e leitura adicionais", os conceitos espontâneos já são em si mesmos "ricos em experiência", mas, devido ao fato de não fazerem parte de um sistema, não fornecem explicações e podem gerar confusões.

Os conceitos espontâneos relacionam-se com o cotidiano e o senso comum, enquanto os conceitos científicos estão relacionados com a teoria, que é construída por pesquisadores e alunos envolvidos em áreas específicas, intencionados em entender ou transformar o mundo (Young, 2002).

Duarte (1996) e Martins (2000) discutem o conceito de cotidiano, diferenciando-o do sinônimo de dia a dia e ampliando-o no sentido de provocar a percepção para além das atividades rotineiras. Para Duarte (1996, p. 32), "As atividades diretamente voltadas para a reprodução do indivíduo, através da qual, indiretamente, contribuem para a reprodução da sociedade, são consideradas atividades cotidianas [...]". Na mesma linha de pensamento, Martins (2000, p. 142) complementa, afirmando que cotidiano "[...] é a mediação que edifica as grandes construções históricas, que levam adiante a humanização do homem [...]". Nesta perspectiva, fica aos educadores mais um desafio no sentido de ampliar seus conhecimentos, vocabulário e entendimento do que tanto se pronuncia na escola - "Faz parte do cotidiano escolar!".

A formação geral, com características de instrução elementar, torna-se insuficiente, quando se pensa em um processo educativo capaz de desenvolver, também, o aprender a ver e a ouvir, trabalhando a sensibilidade e a crítica.

Nos dicionários comuns não localizamos o verbete Dever de Casa. Identifica-se dever (obrigação; ter de; precisar...) e casa (local destinado à habitação; lar; família...). Ausente nos dicionários, mas comum nas escolas, os deveres de casa significam atividades preparadas e designadas pelos professores para que os alunos desenvolvam em casa e apresentam ao professor no outro dia ou no momento marcado. Com um estigma de obrigação, continua sendo pouco discutido entre os profissionais de educação, pois, dependendo da política assumida pela escola, ainda servem de instrumento de controle e punição. 
Localizamos no Dicionário de Educação (VAN ZANTEN, 2011) o verbete Dever de Casa, que apresenta um resgate histórico, indicando que a análise dos textos oficiais da França evidencia um deslocamento progressivo das atividades realizadas em sala de aula para os deveres de casa, fora do horário escolar. Sendo que à elite masculina era dispensado um tratamento diferenciado, em 1802, com a finalidade de formar as "futuras grandes figuras da sociedade" (VAN ZANTEN, 2011, p. 195). Além do trabalho desenvolvido pelo professor, havia a figura do explicador, que desenvolvia atividades focadas na memorização e retórica. Com as mudanças no ensino secundário, o regime de externato e o crescimento do enciclopedismo, observa-se que as salas de estudo iam diminuindo e havendo a fusão das figuras do professor e explicador. Em relação ao ensino primário, havia a preocupação com a saúde e a eficiência dos deveres escritos fora da escola. Era indicado que essas crianças dedicassem mais tempo ao estudo das lições, o que depois foi substituído pelos exercícios escritos, repassando para a família parte da responsabilidade da aprendizagem.

Com a proposta de externalização do estudo, surge um conflito: famílias populares consideravam desfavorável essa situação, enquanto as famílias com mais condições dispunham de outra organização para acompanhamento dessas atividades extraescolares. E os professores também encontravam dificuldades, pois a partir dessa realidade precisavam transmitir os saberes em sala de aula e dirigir os trabalhos realizados em casa. Esse trabalho, ao retornar para sala de aula, recebia uma correção muitas vezes rápida e que não auxiliava o aluno a ampliar seu conhecimento, chegando, em algumas situações, a aumentar as dificuldades apresentadas pelo aluno. Com a ideia de que "[...] é cada vez mais necessário algo diferente da escola para ter êxito na escola [...]" (VAN ZANTEN, 2011, p. 196), persistem as prescrições dos trabalhos escritos em casa. Os professores os justificam como uma das possibilidades para desenvolver a autonomia e uma forma de relacionarem-se com as famílias. Os pais, dependendo de como se envolviam e auxiliavam nesse momento, poderiam orientar os filhos de forma diferenciada da recebida na escola e, assim, contribuir para baixar a motivação dos mesmos. 
O que é pretendido com os deveres de casa pode provocar malentendidos entre professores e alunos, ampliando as diferenças já presentes nas situações de aprendizagens do cotidiano escolar, uma vez que "[...] é impossível saber se os alunos obtêm mais sucesso graças ao trabalho fora da sala de aula ou se fazem esse trabalho por serem bons alunos [...]" (VAN ZANTEN, 2011, p. 197).

Percebe-se, pelo verbete, que as controvérsias quanto à aplicação e objetivos dos deveres de casa não são recentes, implicando em uma condição privilegiada de um explicador ou preceptor. De alguma forma, a escola reforçava (e reforça) as desigualdades econômicas e sociais, não sabendo lidar com as competências e habilidades individuais, e demonstrando dificuldades em trabalhar com as diferentes maneiras de aprender.

A cultura escolar moderna requer um espaço em que as crianças conheçam, exercitem e apliquem códigos de boas maneiras, além de trabalhar com o objetivo de superar o efeito da dispersão, distribuindo os alunos em classes por idade e grau de aprendizado, com tempos específicos para realização das atividades, com castigos e recompensas. O poder e a vigilância, no sentido de garantir um "comportamento padrão" estavam instaurados. Esse perfil confere à escola um novo papel, de reprodução social, acompanhado da emancipação dos indivíduos e das classes populares. Como lugar social, a escola vivencia uma ambiguidade, na qual ideologia e crítica ora se enfrentam, ora se opõem e que, mais tarde, possibilitaram a ampliação dessa identidade escola libertadora ou escola da conformação.

A função da pedagogia entre a conformação, "[...] de reproduzir a sociedade nas suas articulações e no vínculo interiorizado que constitui seu veículo essencial de governo [...]" e a emancipação, como "[...] formação do indivíduo, do sujeito como indivíduo [...]" (CAMBI, 1999, p. 218), vai se estruturando, observando-se mais a função de conformação do que a de emancipação na educação.

Em relação ao currículo formativo, observa-se um movimento de ampliação dos elementos do conhecer e do saber, com novos focos na formação escolar, influenciados pela Matemática, Ciências, História e Geografia. 
À educação é dada a função de construir a consciência de cidadão em cada homem, tornando-se a chave mestra da vida social, sendo o meio mais eficaz para trabalhar com a formação dos indivíduos, garantindo um comportamento homogêneo na sociedade. Neste contexto, a escola se renova, laica e pública, dialogando com as ciências e os saberes em transformação, com um sistema escolar organizado para funcionar e reproduzir a ideologia social. As mulheres e o povo começam a ter direito ao ensino.

Uma das hipóteses que pode ser considerada é a de que a origem dos deveres de casa esteja nas lições sugeridas por Comenius ou através da educação pela instrução proposta por Herbart. É nas prescrições de Comenius em relação à adequação do tempo e aos exercícios de repetição que alguns autores depositam a hipótese da origem dos DC. O referido autor, afirma que "A arte de ensinar nada mais exige, portanto, que uma habilidosa repartição do tempo, das matérias e do método!" (1985, p. 186) e compara a condição do homem à de uma árvore, onde é necessário cuidados para garantir bons frutos, uma boa educação. As cópias, além de desenvolverem a escrita, asseguravam o aprimoramento da caligrafia e ortografia, assim como a segurança e asseio ao escrever, hábitos necessários para os negócios da vida.

$E$, é sobre o ensino das línguas, que o mesmo autor expõe ideias que também nos levam a uma possível origem dos deveres de casa. Refere-se ao tempo dedicado ao estudo público - duas horas antes e duas horas depois do meio dia - e o restante pode ser passado nas "recreações honestas" ou em trabalhos domésticos. Salientando, ainda, que de manhã deve-se cultivar a inteligência e a memória; à tarde, o exercício das mãos e a voz. Porém, em nenhuma situação está explícito que tais exercícios ou tarefas seriam realizados em casa, concepção dada aos deveres de casa neste texto.

A pedagogia herbartiana, com seus passos formais, marcou o ensino expositivo da escola tradicional, trabalhando o caminho do raciocínio do concreto para o abstrato e centrando no educador a tarefa de oferecer ao educando o conhecimento, que posteriormente o aplicaria às situações vividas. E é no último passo, denominado método, em que o aluno aplica o que aprendeu por meio de exercícios, que possivelmente encontre-se a origem dos deveres de casa. 
A instrução escolar sofreu mutações e sintetizando-a em uma fórmula breve, "a escola passou de um contexto de certezas, para um contexto de promessas, inserindo-se, atualmente, em um contexto de incertezas". (CANÁRIO, 2006, p.16). Com essa declaração o autor situa historicamente: a época das certezas, na primeira metade do século $X X$, a escola funcionava como "fábrica de cidadãos", permitindo a ascensão social de alguns e isentando-se da produção de desigualdades. O contexto de promessas é, segundo o autor, posterior à Segunda Guerra Mundial, período que a escola passa de elitista à de massas. E no contexto de diversas qualificações, aumento do desemprego, trabalhos precários e desvalorização dos diplomas escolares e acréscimo das desigualdades, instala-se a escola das incertezas.

Diante desta situação, o autor sugere que as escolas mudem e evoluam para o funcionamento como comunidades de aprendizagem, sendo que o primeiro passo é "organizar os recursos existentes de modo diferente", (CANÁRIO, 2006, p. 19), contrariando a ideia que, inicialmente, toda mudança envolve aumento de recursos.

Referindo-se a dificuldade da escola em atender as demandas sociais, Alarcão (2001) desenvolve o conceito de escola reflexiva ${ }^{2}$, pensando em uma escola como organização de aprendizado, que qualifica tanto estudantes como professores e funcionários. Sobre a função da escola, a mesma autora define que é de "preparar cidadãos, mas não pode ser pensada apenas como tempo de preparação para a vida. Ela é a própria vida, um local de vivência da cidadania", (2001, p.18), referindo-se também à escola como um tempo que não pode ser desperdiçado. Tempo de curiosidade e porque não, de alegria, segundo Snyders (1996). Tempo, também, de "desenvolver e aplicar capacidades como a memorização, a observação, a comparação, a associação, o raciocínio, a expressão, a comunicação" [...] "tempo de atividade e iniciativa.", (ALARCÃO, 2001, p. 18)

\footnotetext{
${ }^{1}$ Grifo das autoras.

${ }^{2}$ Organização (escolar) que continuadamente se pensa a si própria, na sua missão social e na sua organização, e se confronta com o desenrolar da sua atividade em um processo heurístico simultaneamente avaliativo e formativo. (Alarcão, 2001, p. 25).
} 
Canário (2006, p.33) afirma que uma das mais importantes funções da escola é a de "favorecer e incentivar o acesso ao uso da palavra, oral, mas, sobretudo, escrita". Ao aprender a língua, o aluno relaciona-se com o mundo. $\mathrm{Na}$ minha prática educativa, costumo afirmar que a criança, ao dominar os códigos da língua escrita, torna-se independente, "lê"3 o mundo a seu modo, sem precisar depender do outro.

Snyders (1996) descreve que preparar para o futuro e alegria no presente são funções da escola que deveriam complementar-se (p. 29). Faz-se necessário achar um equilíbrio entre o futuro adulto e a criança atual.

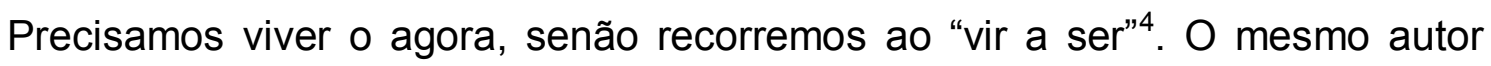
afirma: "Procuro uma escola interessada, interessada em ser, no presente, interessante", (p. 40). Escola esta que seja, realmente, um lugar onde o aluno progrida, com ajuda dos colegas, na relação com professores e funcionários e na relação com as obras e seus criadores.

Referindo-se ao novo sentido para o trabalho escolar, Canário (2006) descreve três orientações fundamentais: "estimular o gosto pelo ato intelectual de aprender, aprender pelo trabalho e exercer o direito à palavra. (p. 20) e relata a experiência de um aluno que, ao ser questionado sobre o que pensava sobre os deveres de casa, resumiu: "Sinto dor no braço!" (p. 21). Atividades estas que não colaboravam no sentido de produzir saberes, mas que representavam uma exaustão, um cansaço. Tal declaração evidencia a ausência de significado ao que foi solicitado e nos remete a um questionamento que deve fazer parte do planejamento de todo professor: qual a minha intenção com tal dever de casa?

\section{O PROFESSOR, O PLANEJAMENTO E OS DEVERES DE CASA}

Foi possível perceber, no mapeamento dos estudos acadêmicos sobre 0 tema, publicados entre os anos 2000 e 2011, na base de dados da Capes e BDTD, que os deveres de casa são um tema com produção acadêmica restrita até 2000, ampliando-se os trabalhos, em especial, a partir de 2005. A

\footnotetext{
${ }^{3}$ Grifo das autoras.

${ }^{4}$ Grifo das autoras.
} 
nomenclatura utilizada para referir-se às atividades pedagógicas propostas pelos professores para que os alunos realizem fora do horário regular das aulas apresenta variações conforme a região brasileira: tema de casa, para casa, lição de casa, tarefa de casa e deveres escolares.

Os estudos sobre os deveres são recentes. Um dos primeiros trabalhos encontrados sobre o tema é o de Fátima Regina Pires de Assis, na área de Psicologia, em 1986, sobre as condições e consequências oferecidas pela escola e o lar para a elaboração da lição de casa. O texto de Marta Guanaes Nogueira (2002), resultado de sua tese de doutorado em Educação defendida em 1998, é bastante referenciado nas pesquisas analisadas e tornou-se livro, com o mesmo título - Tarefa de Casa - Uma violência consentida?.

No texto de Nogueira (2002) encontramos considerações sobre a relação professor e tarefa de casa, explicitando algumas atitudes e estratégias. $\mathrm{O}$ ato de ensinar envolve vários sentimentos e significados, e estes estão entrelaçados aos desafios cotidianos do professor.

A postura do professor, ao elaborar e comunicar sua proposta de deveres de casa, explicita suas intenções enquanto profissional, que pode trabalhar com a ideia de "castigo, punição ou para preencher o tempo livre do aluno"5 como pode proporcionar momentos de desenvolvimento, quando o aluno tem oportunidade de deparar-se com suas dificuldades e facilidades, revendo e ampliando conceitos, fazendo relações com o que aprendeu e a sua vida.

É necessário valorizar a produção, não se limitando ao comum "Visto", como retorno ao tempo e esforço dispensados para os deveres de casa. Outro aspecto a considerar é o entendimento que os deveres de casa fazem parte da aula e devem estar integrados ao planejamento, não se tornando um "apêndice diário"7.

Paula (2000), em sua dissertação, apresentou como objetivo geral "Interrogar as prescrições destinadas para os/as professores/as, expressas nos

\footnotetext{
${ }^{5}$ Grifo das autoras.

${ }^{6}$ Verbete com o significado de [...] percebido pelo sentido da visão, acolhido, considerado, [...], (Ferreira, 2008 , p. 820) e utilizado com frequência nas escolas, indicando que o professor observou que o aluno fez a atividade e/ou deveres de casa.

${ }^{7}$ Grifo das autoras.
} 
Manuais de Didática e na Revista Nova Escola sobre os deveres, tarefas, lições, para casa." e faz referência à dificuldade encontrada durante a sua revisão de bibliografia, ao perceber que os autores:

\begin{abstract}
classificavam tarefa, dever, lição, para casa como aula. Tarefa, dever, para casa é uma lição, ou seja, lição de casa como parte da aula, complemento da aula, continuidade da aula, aula independente, prolongamento da aula, extensão da aula. A dificuldade foi por que eu não entendia a lição de casa como aula, pensava na aula como atividade presencial entre alunos e professor/a. Foi com dificuldade que escutei/detectei os autores da Didática tratando de lição de casa como se tratassem da aula, pressupondo que as características da aula eram continuadas na lição de casa ou compreendendo a atividade como uma das etapas da aula. (PAULA, 2002, p. 75)
\end{abstract}

Nos Manuais, a autora encontrou prescrições de Libâneo, Nérici e da Revista Nova Escola, assinalando que a função dos deveres de casa era um complemento didático, um prolongamento da sala de aula, devendo ser realizado pelo aluno como fixação ou retomada do que foi trabalhado em aula. Identificou que no Ratio Studiorum ${ }^{8}$ podem estar as ideias precursoras das lições de casa:

12. Repetições em casa- Todos os dias, exceto os sábados, os dias feriados e os festivos, designe uma hora de repetição aos nossos escolásticos para que assim se exercitem as inteligências e melhor se esclareçam as dificuldades ocorrentes. Assim um ou dois sejam avisados com antecedência para repetir a lição de memória, mas só por um quarto de hora; em seguida um ou dois formulem objeções e outros tantos respondam; se ainda sobrar tempo, proponham-se dúvidas. E para que sobre, procure o professor conservar rigorosamente a argumentação em forma [silogística]; e quando nada mais de novo se aduz, corte a argumentação. (Ratio II,D,12; grifos e colchete do original, negritos da autora - 2000, p. 104).

Ao concluir sua pesquisa, a autora registra que os deveres de casa não são apenas pedagógicos, mas políticos. Esta prática envolve a família, a escola e a posição do professor, percebendo que a permanência de tal atividade nas escolas justifica-se ora como valor pedagógico, ora como desvalor.

\footnotetext{
${ }^{8}$ Conjunto de normas criado para regulamentar o ensino nos colégios jesuíticos. Sua primeira edição, de 1599, além de sustentar a educação jesuítica ganhou status de norma para toda a Companhia de Jesus. Tinha por finalidade ordenar as atividades, funções e os métodos de avaliação nas escolas jesuíticas.
} 
Nos demais trabalhos identificados é frequente a referência ou dissertação sobre a relação família/escola/deveres de casa, apresentando posições a partir do envolvimento parental em tal momento e das possibilidades de desenvolvimento da criança, registrando a necessidade de ampliação na discussão sobre esta prática na rotina escolar.

\section{CONSIDERAÇÕES E INQUIETAÇÕES}

Este é um assunto que não se esgota... Impossível tecer considerações finais pensando em conclusão, mas é necessário difundir a ideia de que precisamos, na prática, incorporar um olhar mais atento aos deveres de casa, auxiliando na formação docente e problematizando com os colegas que já atuam nas escolas. Pensar em uma prática que oportunize a ampliação do que foi trabalhado na escola, incentivando à pesquisa, à criação, ao refazer a partir de outras possibilidades... Pensando na criança como um ser que se constitui socialmente, estabelecendo relações, que é sujeito da sua história.

O trabalho desenvolvido com os deveres de casa pode ampliar a capacidade da criança, ao mesmo tempo em que, se mal conduzido, pode desenvolver sentimento de incapacidade e resistência à aprendizagem. É necessário trabalhar com os deveres de casa de forma que fiquem explícitas, para todos os envolvidos no cotidiano escolar, sua função e intencionalidade, tornando-se um meio de ampliar os momentos de estudos de cada criança, contribuindo para sua formação pessoal e estudantil. Pensar os deveres de casa, em sua função e abrangência, articulados com os objetivos escolares, constitui-se em um desafio para os professores, para a comunidade escolar... para nós!

\section{LUCIANE MARIA SCHLINDWEIN}

Doutora em Educação (Psicologia da Educação) pela Pontifícia Universidade Católica de São Paulo (PUC/SP). Bolsista de Produtividade em Pesquisa (CNPq) e professora do Programa de Pós-Graduação em Educação (Mestrado e Doutorado) do Centro de Ciências da Educação da Universidade Federal de Santa Catarina (CED/UFSC). 


\section{SILVIANE IRULEGUI BUENO}

Pedagoga pela Pontifícia Universidade Católica do Rio Grande do Sul (PUC/RS). Mestranda em Educação no Programa de Pós-Graduação em Educação da Universidade Federal de Santa Catarina (UFSC).

\section{REFERÊNCIAS}

ALARCÃO, Isabel (Org.). Escola reflexiva e nova racionalidade. Porto Alegre: Artmed, 2001.

ASSIS, Fátima Regina Pires de. Lição de casa: um estudo exploratório sobre as condições e consequências de sua elaboração, em crianças da $1^{a}$ Série do $1^{a}$ Grau. São Paulo, 1986. Dissertação (Mestrado). Instituto de Psicologia, Universidade de São Paulo. 1986.

CAMBI, Franco. História da Pedagogia. Tradução de Álvaro Lorencini. São Paulo: Editora UNESP,1999.

CARDOSO, Miriam L. Questões sobre educação. In: GOULART, Cecília. (Org.). Dimensões e Horizontes da Educação no Brasil. Ensaios em homenagem a Gaudêncio Frigotto, Maria Ciavatta e Osmar Fávero. Niterói, RJ: EduFF, 2004, p. 107-125.

COMÉNIO, J. A. Didáctica Magna. 3. ed. Lisboa: Fundação Calouste Gulbenkian, 1985CANÁRIO, Rui. A escola tem futuro? Das promessas às incertezas. Porto Alegre: Artmed, 2006.

DUARTE, Newton. Educação Escolar, teoria do cotidiano e a escola de Vigotski. Campinas, SP: Autores Associados, 1996.

FERNANDES, Florestan. A formação política e o trabalho do professor. In: CATANI, Denice B. et al. (Org.). Universidade, escola e formação de professores. 2. ed. São Paulo: Brasiliense, 1987, p. 13-37.

FERREIRA, Aurélio Buarque de Holanda. Miniaurélio: o dicionário da Língua Portuguesa. 7 ed. Curitiba: Positivo, 2008.

MARTINS, José de Souza. A sociabilidade do homem simples: cotidiano e história na modernidade anômala. São Paulo: Hucitec, 2000.

MIRANDA, Marília Gouvêa. O processo de socialização na escola: a evolução da condição social da criança. In: LANE, Silvia T. M.; CODO, Wanderley. (Org.). Psicologia social: o homem em movimento. São Paulo, SP: Editora Brasiliense, 1985, p. 125-135. 
NOGUEIRA, Martha Guanaes. Tarefa de casa: uma violência consentida?. São Paulo: Loyola, 2002.

PAULA, Flávia Anastácio. Lições, deveres, tarefas, para casa: velhas e novas prescrições para professoras. 2000. 241p. Dissertação (Mestrado em Educação) - Faculdade de Educação, Universidade Estadual de Campinas, 2000.

SNYDERS, Georges. Alunos felizes: reflexão sobre a alegria na escola a partir de textos literários. $2^{a}$ ed. São Paulo: Paz e Terra, 1996.

VAN ZANTEN, Agnès. (Coord.). Dicionário de Educação. Petrópolis, RJ:Vozes, 2011.

YOUNG, M. Durkheim, Vygostsky e o Currículo do Futuro. Trad. Maria Lúcia Mendes Gomes, Regina Thompson e Vera Luiza Visackis Macedo. In: Cadernos de Pesquisa, n. 117, p. 53-80, nov./2002.

Para que servem as escolas? Tradução de Márcia Barroso, com revisão técnica de Maria Inês Marcondes. In: Educação e Sociedade, Campinas, vol. 28, n. 101, p. 1287-1302, set/dez. 2007. 